\title{
Critical Incidents in Engineering Students' Development of More Compre-hensive Ways of Experiencing Innovation
}

\author{
Dr. Nicholas D. Fila, lowa State University
}

Nicholas D. Fila is a postdoctoral research associate in Electrical and Computer Engineering and Industrial Design at lowa State University. He earned a B.S. in Electrical Engineering and a M.S. in Electrical and Computer Engineering from the University of Illinois at Urbana-Champaign and a Ph.D. in Engineering Education from Purdue University. His current research interests include innovation, empathy, design thinking, and instructional design heuristics.

Dr. Justin L. Hess, Indiana University-Purdue University of Indianapolis

Dr. Justin L Hess is the Assistant Director of the STEM Education Innovation and Research Institute at IUPUI. His research interests include ethics, design, and sustainability. Dr. Hess received each of his degrees from Purdue University, including a $\mathrm{PhD}$ in Engineering Education, a Master of Science in Civil Engineering, and a Bachelor of Science in Civil Engineering. He is currently the Vice Chair of the American Society of Civil Engineers' Committee on Sustainability subcommittee on Formal Engineering Education.

This is the author's manuscript of the article published in final edited form as:

Fila, N. D., \& Hess, J. L. (2018). Critical Incidents in Engineering Students' Development of More Comprehensive Ways of Experiencing Innovation. Presented at the 2018 ASEE Annual Conference \& Exposition. Retrieved from https://peer.asee.org/ critical-incidents-in-engineering-students-development-of-more-comprehensive-ways-of-experiencing-innovation 


\section{Critical Incidents in Engineering Students' Development of More Comprehensive Ways of Experiencing Innovation}

\section{Introduction}

Recent years have seen an increased emphasis placed on innovation among engineering students. This is evident in the variety of courses, workshops, programs, and communities that currently support innovation and innovation learning ${ }^{1-4}$. Likewise, there is a growing volume of research dedicated to understanding the contexts, conditions, and experiences that promote innovative outcomes, knowledge, skills, and mindsets among engineering students ${ }^{5-9}$. Collectively, these investigations and efforts paint a complex and diverse landscape of engineering innovation and student learning. Within this landscape, innovation can take many forms, arise from different conditions, and rely on various contextual and situational nuances.

It is important to note that this diversity of innovation education practices and settings reflects the diversity in processes, definitions, and characteristics that are aligned with innovation. For example, a recent study demonstrated twenty unique characteristics of engineering innovators that a lone individual is unlikely to possess ${ }^{10}$, while a study of innovator's processes found over 140 distinct activities connected to innovation ${ }^{11}$. Thus, engineers and engineering students are likely to find different ways to become innovative and/or demonstrate innovation, which may create unique challenges for innovation educators.

To address this need, qualitative studies have explored common or transferable factors that support innovative development in different ways and across settings. One approach has been to explore the experiences of recognized innovators and identify commonalities. For example, a recent study identified six themes that 60 expert innovators deemed critical to the development of their innovation abilities ${ }^{12}$. These themes cut across settings and spoke to key experiences that helped illuminate unique aspects of innovation and reframe their approaches. Another approach has been to identify student differences with respect to innovation and explore reasons for those differences. For example, a recent study highlighted eight distinct ways in which engineering students approached and understood innovation, each featuring different understandings of innovation processes and focus areas (technical, human, and enterprise) ${ }^{13}$. A follow-up study identified three overarching themes representing different ways students came to those diverse understandings, but also several contextual and individual characteristics that were unique to each category of innovation approach and understanding ${ }^{14}$.

This study presents a third approach that builds upon and complements these previous findings. We combine thematic analysis procedures ${ }^{15}$ with critical incident technique ${ }^{16,17}$ to (1) explore fine-grained experiences and aspects therein that contributed to new ways of understanding innovation and (2) identify similar types of experiences they may be applicable across settings. By utilizing these qualitative research techniques, we sought to address the research question, "What aspects of engineering students' innovation experiences were critical to the development of their ways of experiencing innovation?" 


\section{Conceptual Background}

This study builds upon a previous study that explored differences in the ways engineering students experienced innovation ${ }^{13}$. The current study expands the previous by exploring critical incidents that led to new or refined understandings of innovation, but it is necessarily rooted in the theoretical underpinnings and findings of the previous study. In this section, we summarize the previous study and discuss how it informs the current investigation.

The genesis of this project was a phenomenographic analysis of innovation among engineering students. Phenomenography is a qualitative research technique that typically uses extended, semi-structured interviews to identify distinct categories of description representing similarities in the ways a group of participants understands, relates to, and experiences a phenomenon (e.g., innovation ${ }^{18,19}$. The relationships between these categories are demonstrated in an outcome space that demonstrates the variety in ways of experiencing the phenomenon (i.e., categories of description), as well as ways in which the categories build upon one another.

In the previous study, eight distinct categories of description emerged. Each category was comprised of the experiences of three to seven participants (out of a population of 33) who shared critical and distinct commonalities in their individual ways of experiencing innovation (see Table 1). These categories formed a hierarchical progression from less comprehensive to more comprehensive ways of experiencing innovation along two dimensions: Focus of Innovation Activities and Extent of Innovation Process (see Figure 1). It should be noted that the final four categories (5-8) were each at the highest level of comprehensiveness in the outcome space. They differed primarily on the Focus of Innovation Activities dimension.

The Focus of Innovation Activities dimension addressed the area(s) that individuals prioritized during innovation activities (e.g., technical, human, or enterprise). In less comprehensive categories (1-4), this dimension represented participants' expanding awareness of focus areas within innovation, moving from solely technical development, to acknowledging user considerations, to adding and prioritizing business considerations. The more comprehensive categories (5-8) each detailed technical, human, and enterprise aspects, but each prioritized them to different degrees.

The Process dimension described the phase(s) of an engineering project during which innovative activity occurred. Participants within one category may have been aware of phases outside their category's placement, but their descriptions of the innovation experience were predominantly focused on the phases aligned with their category. In less comprehensive categories (1-4), this dimension represented participants' expanding awareness of increasingly front-end phases of innovation, adding idea generation, problem scoping, and problem finding with each progressive category. Categories that represented more comprehensive ways of experiencing innovation (5-

8) acknowledged each of four phases describing a single engineering project from beginning to end, but also acknowledged that these projects existed within a larger developmental cycle. In other words, innovation did not only occur within the confines of a single project but could continue to be improved during follow-up projects or inspire others to develop future innovations. 
Table 1. Summaries of the Eight Ways of Experiencing Innovation

\begin{tabular}{|c|c|}
\hline Category & \\
\hline $\begin{array}{l}1-\text { Realize } \\
\text { technological } \\
\text { function }\end{array}$ & $\begin{array}{l}\text { Innovation is solving a personally novel and ill-defined problem. The solution need not be } \\
\text { globally novel. It simply must meet given technical/functional criteria. Innovation is in the } \\
\text { creative thinking needed to accomplish a task you do not already know how to accomplish. } \\
\text { This process is marked by quickly identifying potential solutions, building and testing them, } \\
\text { and modifying solutions until an adequate solution is found (e.g., trial-and-error, barnyard } \\
\text { engineering, etc.). }\end{array}$ \\
\hline $\begin{array}{l}2-\text { Redesign and } \\
\text { realize to meet } \\
\text { stakeholder } \\
\text { criteria }\end{array}$ & $\begin{array}{l}\text { Innovation is redesigning something to benefit a group of stakeholders. These problems focus } \\
\text { on implementing a specific technical function that arises from stakeholder needs. Innovation } \\
\text { starts with understanding a current or conceptual solution to the stakeholder problem and how } \\
\text { it does not meet the requirements, then follows with a thorough idea generation process to } \\
\text { imagine new solutions and a design-build-test process until the new, stakeholder-appropriate } \\
\text { solution is realized. }\end{array}$ \\
\hline $\begin{array}{l}3 \text { - Clarify and } \\
\text { solve a } \\
\text { stakeholder } \\
\text { problem }\end{array}$ & $\begin{array}{l}\text { novation is identifying and solving a problem for a specific stakeholder group. This first } \\
\text { quires investigating the context to gain an understanding of the users and the specifics of a } \\
\text { neral problem. Then it involves generating ideas and working toward developing an idea } \\
\text { at is feasible and meets the other criteria. Innovation represents a solution that meets the } \\
\text { tlined criteria and requires the innovator's own unique perspective and expertise. }\end{array}$ \\
\hline $\begin{array}{l}4 \text { - Identif } \\
\text { fill a marke }\end{array}$ & $\begin{array}{l}\text { Innovation is creating a solution that would be successful in a market because it offers } \\
\text { substantial improvement over existing solutions or solves a problem that was not previously } \\
\text { solved. A key activity here is in identifying an underserved market and finding problem to } \\
\text { solve. While technical and human aspects are considered, the focus is on whether the solution } \\
\text { would achieve market success (i.e., profitability, market acceptance), and thus benefit an } \\
\text { enterprise. }\end{array}$ \\
\hline $\begin{array}{l}5-\text { Deve } \\
\text { solution } \\
\text { client be }\end{array}$ & $\begin{array}{l}\text { Innovation is creating new solutions for the benefit of a specific client. Innovators are aware of } \\
\text { and care about many stakeholders, including teammates, users, and others, but they prioritize } \\
\text { client needs due to an awareness of who the project is intended to serve and a reliance on } \\
\text { client-provided resources. Innovators realize they can better serve other stakeholders } \\
\text { (including themselves) and further advance technology through a series of small, client- } \\
\text { serving advancements. }\end{array}$ \\
\hline $\begin{array}{l}6 \text { - Develop new } \\
\text { solution to make } \\
\text { a difference for } \\
\text { users }\end{array}$ & $\begin{array}{l}\text { Innovation is making change for a specific user group. This process requires a deep } \\
\text { understanding or the users and the context in which the solution will be implemented. While } \\
\text { technical, financial, and resource constraints play a role, the innovators prioritize meeting user } \\
\text { needs. This can include passing on options that may be more technologically or personally } \\
\text { interesting and novel. Innovations during one project support innovations during later projects } \\
\text { by growing innovator-user relationships and/or acting as a platform to create even more } \\
\text { beneficial solutions. }\end{array}$ \\
\hline $\begin{array}{l}7-\text { Deve } \\
\text { technolo } \\
\text { societal p }\end{array}$ & $\begin{array}{l}\text { Innovation is introducing new technological advancements that represent progress for users, } \\
\text { communities, and society. Oftentimes, these innovations involve developing new products or } \\
\text { systems for specific stakeholders and contexts, with the awareness that the knowledge and } \\
\text { solutions created will support the development of future innovations and societal progress } \\
\text { elsewhere. Often, these innovators are concerned mostly with technological feasibility because } \\
\text { they are aware they will have the opportunity to enhance the product/system in future } \\
\text { iterations. }\end{array}$ \\
\hline $\begin{array}{l}8-\text { Develop } \\
\text { radically new } \\
\text { technology }\end{array}$ & $\begin{array}{l}\text { Innovation is developing new technology that is revolutionary in an industry. The innovator } \\
\text { develops an idea for a new technology by applying scientific and engineering principles in a } \\
\text { novel way and works to turn the idea into a feasible prototype/product. While this process } \\
\text { typically does not involve considering the needs of direct users, the potential applications and } \\
\text { additional advancements from knowledge created will affect the lives of many and may } \\
\text { motivate the innovator. }\end{array}$ \\
\hline
\end{tabular}




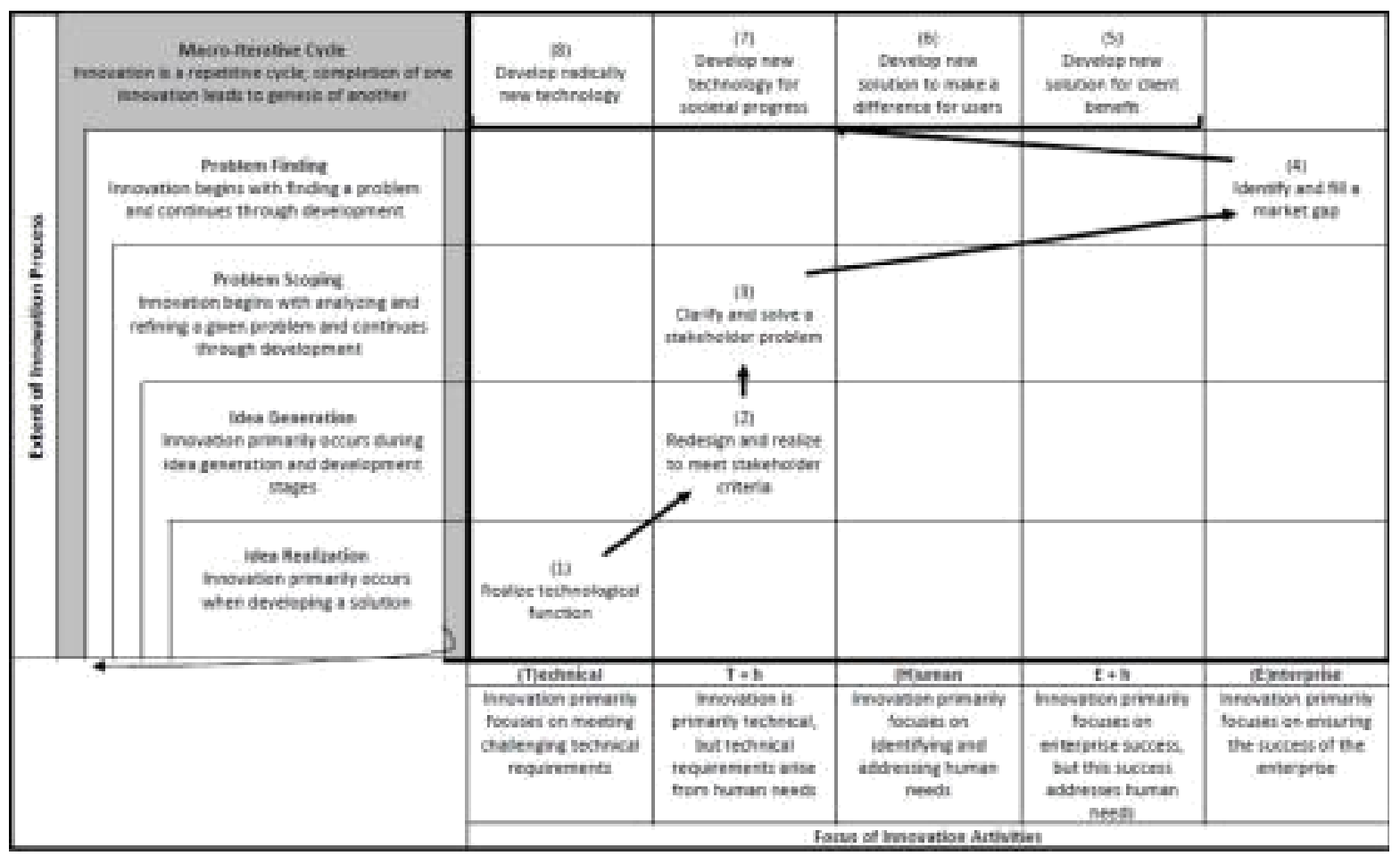

Figure 1. Innovation Outcome Space (from Anonymous)

These results (1) frame the phenomenon of innovation by its process elements and focal considerations, (2) present common groupings of student understanding within this framework, and (3) suggests a logical, hierarchical progression to more comprehensive ways of experiencing innovation. While this framework does not necessarily address all desired innovation learning outcomes (e.g., individual characteristics ${ }^{10}$, creativity ${ }^{8}$, and ability to produce objectively innovative solutions to engineering problems ${ }^{7}$ ), more comprehensive categories demonstrate broader and more flexible perspectives on innovation, increased awareness of different approaches and considerations within innovative work, and deeper connections between the individual and the phenomenon of innovation. Thus, the question of how individuals transition to more comprehensive categories becomes important to educators and researchers interested in the development of engineering innovators.

The outcome space in Figure 1 demonstrates a logical progression to more comprehensive categories (e.g., the transition from Category 1 to Category 2 may result from projects with a greater focus on stakeholders and awareness of limitations in existing solutions), but these transitions do not necessarily demonstrate the ways that students advance to more comprehensive categories. In an initial follow-up study, we utilized thematic analysis ${ }^{15}$ to explore movement towards more comprehensive categories based on students' firsthand accounts of their innovation experiences. This analysis resulted in three themes showing that three factors influenced development of more comprehensive ways of experiencing innovation: (1) more complete projects, (2) experiences aligned with one's interests and engineering goals, and (3) persistent tensions and acute failures. These results suggest that a more fine-grained analysis could help demonstrate, more specifically, how the experiences imbued within these themes directly supported innovation learning outcomes. For example, what aspects of a "complete" project experience supported innovation learning outcomes, and which were most critical? 


\section{Methods}

We used the Critical Incident Technique (CIT) ${ }^{16,17}$ to explore how engineering students progress from less to more comprehensive ways of experiencing innovation. CIT seeks to identify and categorize core features that contribute to growth in or mastery of a task or process. The method traces its roots back to World War II, where it was implemented to explore leadership development and pilot training ${ }^{16}$. Within the context of engineering education, CIT was recently applied to understand key experiences that supported perspective-taking development among engineering students ${ }^{20}$. In this study, we sought to identify critical incidents within the firsthand accounts of innovation experiences from engineering students, who demonstrated a range of perspectives on and experiences with innovation.

\section{Participants}

Participants were purposefully selected from an initial pool of 33 engineering students who participated in an extended interview that explored their experiences with innovation. In contrast to the original purpose of the interview, which was to identify variation in students' experiences with innovation, this study sought to identify incidents that contributed to movement from less to more comprehensive understandings of innovation. The sample in this study included a subset of the original 33 students. This sample represented nine different majors who had participated in over 30 unique innovation projects (Table 2). The participants were each enrolled in a large Midwestern university and were purposefully selected to achieve maximum variation along four key factors: way of experiencing innovation (see Table 1), gender (one male and one female per way of experiencing innovation, when possible), academic major (distinction in student discipline), and year in school. Each of these factors were previously found to affect one's experiences with innovation ${ }^{13,14}$. Participants are listed by a pseudonym they selected.

\section{Data Collection}

The engineering students each participated in a 1-2 hour semi-structured phenomenographic interview ${ }^{19}$ and received a small cash incentive for participation. The purpose of these interviews was to elicit student's perspectives and experiences with innovative design. The interviews occurred in six stages defined by the topical focus of the questions: (1) participant background,

(2) initial definition of innovation, (3) experiences during innovation projects, (4) comparison of innovative and non-innovative projects, (5) general conceptions of innovation, and (6) closing thoughts. One difference between these interviews and standard phenomenographic interviews was an emphasis on participant background questions. This emphasis was added due to the importance of developing an empathic understanding of the participant in phenomenographic research ${ }^{21}$. It also supported deeper and more comprehensive portraits of each participant for the current study. This increased focus on participant background helped to contextualize the critical incidents we identified, explored, and synthesized. Students also completed a short multiple choice and open-response survey which primarily included demographic information. All interviews were audio-recorded and later transcribed for analysis. 
Table 2. Participant Overview

\begin{tabular}{|c|c|c|c|c|c|}
\hline Pseudonym & $\begin{array}{l}\text { Way of } \\
\text { Experiencing } \\
\text { Innovation }\end{array}$ & Major & Year & Gender & $\begin{array}{l}\text { Engineering Innovation } \\
\text { Project Experience }\end{array}$ \\
\hline Jerry & $\begin{array}{l}\text { Realize technological } \\
\text { function }\end{array}$ & First-year & First-year & Male & $\begin{array}{l}\text { Design competition club team; } \\
\text { Personal projects }\end{array}$ \\
\hline Matt & $\begin{array}{l}\text { Realize technological } \\
\text { function }\end{array}$ & Mechanical & Senior & Male & $\begin{array}{l}\text { Sophomore design, Service } \\
\text { learning }\end{array}$ \\
\hline Hannah & $\begin{array}{l}\text { Redesign to meet } \\
\text { stakeholder criteria }\end{array}$ & Chemical & Sophomore & Female & $\begin{array}{l}\text { Service learning, Design } \\
\text { competition club team }\end{array}$ \\
\hline Snow & $\begin{array}{l}\text { Redesign to meet } \\
\text { stakeholder criteria }\end{array}$ & Mechanical & Senior & Male & Co-op \\
\hline Maria & $\begin{array}{l}\text { Clarify and solve a } \\
\text { stakeholder problem }\end{array}$ & Industrial & Junior & Female & $\begin{array}{l}\text { Internship, Class Projects, } \\
\text { Student Organization }\end{array}$ \\
\hline Tony & $\begin{array}{l}\text { Clarify and solve a } \\
\text { stakeholder problem }\end{array}$ & Industrial & Senior & Male & Service learning, Senior design \\
\hline Esteban & $\begin{array}{l}\text { Identify and fill a } \\
\text { market gap }\end{array}$ & First-year & First-year & Male & $\begin{array}{l}\text { Self-initiated start-ups; First- } \\
\text { year engineering design projects }\end{array}$ \\
\hline Jessica & $\begin{array}{l}\text { Identify and fill a } \\
\text { market gap }\end{array}$ & Biological & Sophomore & Female & $\begin{array}{l}\text { Course projects, Club projects, } \\
\text { Personal projects }\end{array}$ \\
\hline Ella & $\begin{array}{l}\text { Develop new } \\
\text { solutions for client } \\
\text { benefit }\end{array}$ & Industrial & Senior & Female & $\begin{array}{l}\text { Internships, Service learning, } \\
\text { Personal projects, Service } \\
\text { learning club }\end{array}$ \\
\hline Verdasco & $\begin{array}{l}\text { Develop new } \\
\text { solutions for client } \\
\text { benefit }\end{array}$ & Mechanical & Junior & Male & $\begin{array}{l}\text { Service learning, First-year } \\
\text { course project }\end{array}$ \\
\hline Elon & $\begin{array}{l}\text { Develop new } \\
\text { solutions to make a } \\
\text { difference for users }\end{array}$ & Mechanical & Senior & Male & $\begin{array}{l}\text { Co-op, Internships, Sophomore } \\
\text { design, Design competition club } \\
\text { team, Personal projects }\end{array}$ \\
\hline Sarah & $\begin{array}{l}\text { Develop new } \\
\text { solutions to make a } \\
\text { difference for users }\end{array}$ & Chemical & Senior & Female & Service learning, Internships \\
\hline Dylan & $\begin{array}{l}\text { Develop new } \\
\text { technology for } \\
\text { societal progress }\end{array}$ & Biomedical & Senior & Male & Senior design, Internships \\
\hline Taylor & $\begin{array}{l}\text { Develop new } \\
\text { technology for } \\
\text { societal progress }\end{array}$ & Computer & Senior & Female & $\begin{array}{l}\text { Junior-level course projects, } \\
\text { First-year engineering course, } \\
\text { Internship, Student } \\
\text { organizations, Personal robotics } \\
\text { project }\end{array}$ \\
\hline Chris & $\begin{array}{l}\text { Develop radically } \\
\text { new technology }\end{array}$ & Nuclear & Graduate & Male & Long-term personal start-up \\
\hline John & $\begin{array}{l}\text { Develop radically } \\
\text { new technology }\end{array}$ & Acoustical & Senior & Female & $\begin{array}{l}\text { First-year engineering course, } \\
\text { Service learning, Internship }\end{array}$ \\
\hline
\end{tabular}


We used Critical Incident Technique ${ }^{16,17}$ to identify and analyze incidents that demonstrated growth in the way engineering students experienced innovation. In this study, critical incidents were systematically extracted from interviews using the following criterion: A critical incident includes any event, extracted from students' verbal responses, in which a student described or demonstrated a change, refinement, or crystallization of their way of understanding the act, process, idea, or nature of innovation, or their approach toward innovation. We did not judge what qualified as innovation. Rather, if a participant identified an experience as an innovative experience, we classified it as such. However, as described above, we recognize that there exists variation in how individuals experience innovation (see Table 1) and we adopted this same framing in variation herein.

We used Butterfield and colleagues ${ }^{17}$ suggestions when setting criteria for incidents. Specifically, they indicated that critical incidents must include three aspects: (1) antecedent information, (2) a detailed description of the experience, and (3) and an outcome of the incident (p. 488). As we reviewed interview passages, we similarly sought three components:

1. Description or demonstration of one or more aspects of understanding or approaching innovation. Direct connections to innovation were preferred, but this connection could be inferred from a participant's category of description (as seen in the previous study ${ }^{13}$ ) or contextual cues in the interview and/or excerpt.

2. Detailed description of an experience or series of experiences that are directly attributable to the aspect(s) of their way of understanding or approaching innovation.

3. A clear change, refinement, or crystallization in one's view of innovation, especially as it addressed aspects of that participant's way of experiencing innovation ${ }^{13}$.

The process began with Author 1 extracting potential incidents that met the above criteria. Author 2 then reviewed the incidents and indicated level of agreement (agree, maybe, or disagree). Author 2 provided a supporting statement for that ranking, especially when disagreeing or indicating "maybe." Authors 1 and 2 then met to discuss all comments, with a focus on non-agreements. The authors both described their rationale, reviewed the original excerpts and transcript text, and discussed whether the incident met the necessary criteria. Discussion ended when both authors agreed to remove or retain the critical incident. Through this process, 140 incidents were retained for analysis. Incidents could be as brief as a 10-sentence paragraph or as long as 4 pages, and often spanned one to two pages.

\section{Data Analysis - Identifying Categories of Critical Incidents}

Once the critical incident selection was finalized, Author 1 began categorizing incidents into like-groups, using thematic analysis as a methodological grounding ${ }^{15}$. Thematic analysis is the process of inductively identifying patterns within a dataset through iterative coding and theme formation. We adapted Braun and Clarke's ${ }^{15}$ recommendations for thematic analysis into a fivestage process for categorizing the critical incidents: 
1. Reading and rereading the critical incidents to understand the breadth and depth of the critical incidents

2. Generating emergent codes that represent unique aspects of the critical incidents

3. Identifying themes that define unique categories of critical incidents through finding patterns in the codes from step 2

4. Checking themes against the individual excerpts (i.e., critical incidents) and the entire data set to ensure that similar critical incidents are grouped together and the categories accurately convey the scope of the critical incidents identified

5. Building narratives around the categories to support connections to extant knowledge of student innovation development and practical classroom applications.

The overall objective of this categorization was to generate core categories that encapsulated the critical components for promoting students' novel or more comprehensive understandings of and approaches to innovation. We also sought to ensure that the categories were cohesive (i.e., that critical incidents did not just share superficial connections but represented similar developmental experiences). The process was iterative and non-linear. In other words, Author 1 did not necessarily move through steps 1-5 in order, but rather would continually revisit prior steps in a cyclical manner. The final categories emerged as related to the environmental features from which students learned, as well as the ways in which students interacted with those environments (which is aligned with the nondualist ontology that underpinned the original formation of the categories of description in the previous study ${ }^{13,18,19}$ ). Author 1 discussed the final categorization with Author 2 to provide an additional check for validation and trustworthiness.

\section{Results}

We identified 140 critical incidents among the 16 interviews. Interviews contained between four and 15 incidents. Incidents were mostly situated in the participants' primary undergraduate innovation projects, but also involved experiences as early as elementary school. Through our analysis, we found 10 unique types of critical incident, which we have further grouped into four categories (see Table 2). Importantly, we do not infer the magnitude of change of the incident types. Rather, we only suggest that these outcomes were potential generators or causes of student development along the outcome space described in Figure 1. In other words, more pervasive incidents should not necessarily be considered "ideal." Further, we were unable to categorize 18 incidents. Hence, while the results in Table 3 are nearly exhaustive, we recognize that there are other modes, incidents, or experiences that contribute to student innovation. In other words, we do not presuppose that these findings portray all modes of innovation development.

In the following sections, we describe each type of incident and provide excerpts to demonstrate incident grouping. This thick description also provides an opportunity for the reader to discern their own self-perception of the alignment between the incident and the broader incident type. Rather than radically condensing incidents, the provided excerpts tend towards extensiveness in our attempt to thoroughly demonstrate both the potential cause and outcome of the critical incident. Nonetheless, we attempted to abridge incidents whenever possible and in a manner that we felt retained the essence of the excerpt. For example, when reporting excerpts, "..." indicates a slight skip in the excerpt (i.e., a few sentences), whereas "[...]" represents moderate skips (i.e., one to several paragraphs). 
Table 2. Categories of Critical Incidents

\begin{tabular}{|c|c|c|c|}
\hline Category & Incident Type & Description & $\begin{array}{l}\text { Participants } \\
\text { (\# of incidents) }\end{array}$ \\
\hline \multirow[t]{2}{*}{$\begin{array}{l}\text { Learning from } \\
\text { Immersion }\end{array}$} & Trying New Approaches & $\begin{array}{l}\text { Forced to try new approaches due to project } \\
\text { requirements, constraints, environments, and/or } \\
\text { roles forced. These included general } \\
\text { approaches/mindsets, modifications of one's } \\
\text { existing approaches, or specific methods/tools. } \\
\text { Built views of innovation to align with these new } \\
\text { approaches. }\end{array}$ & $\begin{array}{l}\text { Ella (2), Hannah } \\
\text { (3), Jessica (3), } \\
\text { Maria (1), Sarah } \\
\text { (3), Taylor (1), } \\
\text { Dylan (1), Esteban } \\
\text { (3), Jerry (1), } \\
\text { Tony (2), } \\
\text { Verdasco (2) }\end{array}$ \\
\hline & $\begin{array}{l}\text { Immersion in Novel } \\
\text { Innovation Ecosystems }\end{array}$ & $\begin{array}{l}\text { Experienced new elements of innovation due to } \\
\text { substantive involvement in authentic innovation } \\
\text { projects firsthand and reflecting on these new } \\
\text { facets. Developed a broader understanding of the } \\
\text { innovation ecosystem. }\end{array}$ & $\begin{array}{l}\text { Ella (4), Hannah } \\
\text { (1), Jessica (2), } \\
\text { John (1), Sarah } \\
\text { (3), Verdasco (3) }\end{array}$ \\
\hline \multirow[t]{2}{*}{$\begin{array}{l}\text { Learning from } \\
\text { Failure }\end{array}$} & Acute Failure & $\begin{array}{l}\text { Experienced a failed prototype or implemented } \\
\text { design due to their natural approaches. They } \\
\text { hated this failure, reflected on their approaches, } \\
\text { and tried new approaches. }\end{array}$ & $\begin{array}{l}\text { Elon (1), Esteban } \\
(1), \text { Jerry (2) }\end{array}$ \\
\hline & Responding to Setbacks & $\begin{array}{l}\text { Recognized, within the process, that something } \\
\text { was not working and a change was needed (not as } \\
\text { acute as failure). Led to recognition of essential } \\
\text { mindsets and approaches to innovation. }\end{array}$ & $\begin{array}{l}\text { Hannah (1), John } \\
\text { (2), Jerry (1), } \\
\text { Verdasco (1) }\end{array}$ \\
\hline \multirow[t]{3}{*}{$\begin{array}{l}\text { Learning from } \\
\text { Others }\end{array}$} & Observing Colleagues & $\begin{array}{l}\text { Observed the ideas and approaches of others and } \\
\text { used these observations to come to new } \\
\text { realizations about how innovation occurs. There } \\
\text { were positive and negative examples. Some saw } \\
\text { innovative things others did while others saw how } \\
\text { others' approaches were limited. }\end{array}$ & $\begin{array}{l}\text { Ella (2), John (1), } \\
\text { Sarah (2), Taylor } \\
\text { (1), Chris (2), } \\
\text { Elon (1), Tony (1), } \\
\text { Verdasco (1) }\end{array}$ \\
\hline & $\begin{array}{l}\text { Reflecting on Historical } \\
\text { Examples }\end{array}$ & $\begin{array}{l}\text { Connected examples of innovations and their } \\
\text { development and connected these messages to } \\
\text { their own experience. Led to insights about what } \\
\text { innovation is and how it occurs. }\end{array}$ & $\begin{array}{l}\text { Hannah (1), Sarah } \\
\text { (1), Taylor (1), } \\
\text { Chris (3), Dylan } \\
\text { (1), Jerry (1), } \\
\text { Snow (2), Tony } \\
\text { (1) }\end{array}$ \\
\hline & $\begin{array}{l}\text { Responding to External } \\
\text { Evaluation }\end{array}$ & $\begin{array}{l}\text { Work was judged by an expert or authority to be } \\
\text { innovative. Refined definition of innovation in } \\
\text { alignment the authority's assessment (e.g., a } \\
\text { broadened definition of innovation). }\end{array}$ & $\begin{array}{l}\text { Elon (1), Esteban } \\
\text { (1) }\end{array}$ \\
\hline \multirow[t]{3}{*}{$\begin{array}{l}\text { Learning from } \\
\text { Success }\end{array}$} & $\begin{array}{l}\text { Reflection on Project } \\
\text { Conditions }\end{array}$ & $\begin{array}{l}\text { Reflected on the project conditions that supported } \\
\text { or did not support innovation. This could include } \\
\text { positive or negative examples, but more } \\
\text { commonly involved contrasting innovative and } \\
\text { non-innovative projects. }\end{array}$ & $\begin{array}{l}\text { Hannah (2), } \\
\text { Jessica (2), Maria } \\
\text { (2), Sarah (3), } \\
\text { Taylor (5), Chris } \\
\text { (1), Dylan (5), } \\
\text { Elon (1), Esteban } \\
\text { (1), Matt (3), Tony } \\
\text { (1) }\end{array}$ \\
\hline & "Hey, That Worked" & $\begin{array}{l}\text { Recognized a specific action that that led to an } \\
\text { innovative idea. Often this was not explicitly } \\
\text { directed at innovation but resulted in innovation } \\
\text { all the same. Expanded understanding of how } \\
\text { innovation occurs. }\end{array}$ & $\begin{array}{l}\text { Ella (1), Sarah (2), } \\
\text { Chris (2), Dylan } \\
\text { (2), Snow (2) }\end{array}$ \\
\hline & "I'll Do It My Way" & $\begin{array}{l}\text { Utilized approaches to innovation that came } \\
\text { naturally or connected to prior interests. This may } \\
\text { have involved sense-making or recognizing that } \\
\text { an approach was effective for innovation. }\end{array}$ & $\begin{array}{l}\text { Hannah (3), } \\
\text { Taylor (1), Chris } \\
\text { (3), Jerry (1), Matt } \\
\text { (5), Snow (2), } \\
\text { Tony (3) }\end{array}$ \\
\hline
\end{tabular}




\section{Learning from Immersion}

The first category of critical incident types focused on immersive learning. In these types of incidents, participants became deeply engaged in novel innovation contexts and developed new understandings of innovation due to trying new approaches, playing new roles, and considering these in light of environmental factors. Incidents in this category often involved participants struggling to resolve differences between the elements of innovation within the new contexts visà-vis their prior approaches and understandings. The two types of incident within this category included Trying New Approaches and Immersion in a Novel Innovation Ecosystem.

\section{Trying New Approaches}

In this type of incident, participants engaged with novel innovation approaches as dictated or inspired by their project contexts. These were not approaches that came naturally to the participants. Most approaches were initiated by requirements or guidelines defined by clients, instructors and/or supervisors, or adjustments participants needed to make due to novel roles or contextual factors. Incidents could be as specific as using a new design tool or performing a specific task (e.g., a weighted decision matrix); documenting and/or considering a new criterion, constraint, or focus area (e.g., users, marketability); or adhering to new project management structure (e.g., a set of milestones/deadlines).

In some cases, these approaches were restrictive initially. For example, Hannah felt that the documentation aspect detracted from her technical design work, which was where she believed innovation was occurring.

We have this big design document... It's a 15 or 16 page document that we had to write about the project partner... So, obviously, we wanted to record what went on. Each failure, why it went wrong, things like that. But a lot of it was like, "this is our project partner." They wanted us to learn personally about them, and it was just like, "I want to do the design!" Well, you need to know about the project partner to figure out what they want for the design, obviously, but it was hard to communicate and do all that. So, we were wasting our time more doing the design document about the [user group and context]... It was also we wanted to see what we could do, we wanted to see what other things we could explore, but ultimately, we were working for the project partner. Ultimately, we needed to get something done for them and figure out what the best product possible was for their needs to get it to them on the table on time. That was the ultimate goal... I guess it really didn't take away from being innovative, now that I think about it. It helped us learn more about what we could do, what they wanted. (Hannah, Sophomore, Chemical Engineering)

However, as participants tested these new approaches they often found value in and new understandings of innovative practices, such as in regards to its processual dimensions and focus areas. Hannah, for example, found that by documenting user information, she developed a better understanding of how technical requirements came from user needs, and how understanding users was an important precursor to the technical design aspects of innovation (which was a defining feature of her category of description: Redesign to Meet Stakeholder Criteria). 
In other cases, the new, guided approaches provided structure in an area of felt difficulty for the students, or the new approach provided an interesting synergy with their extant interests and approaches. Students readily connected to these novel approaches and came to understand them as essential facets of innovation. Participants like Jessica began to incorporate perspectives from marketing from two food process design projects to guide her problem framing work and considerations of user acceptance. Similarly, Dylan connected the structure provided by firm deliverable deadlines from his senior design project to his feasibility-oriented approach to innovation.

There's a lot of trust within our instructors. They've done this before, so they know when the timeline between the paperwork, meetings, prototyping, showing, how it should go. So, the mindset typically is, "we know in the end we will have a final product, but at the end of this week what do we have to have done to meet that goal." So that's always been the mindset, you take it by baby steps, you know you take it by little steps and then it all adds up to be one big step. And that's always been the mindset, just make sure that we can meet our checkpoints so that we can actually make what we said we wanted to make...

If you're missing the deadlines, it might let you know about the feasibility of the project. So, if you can't meet, if you can't produce a prototype of it by this Friday, then it's like, "Well, why can't you?" Though you want to be innovative, if you can't adequately make it innovative in the right amount of time it's clear that you're not going to be able to do it long term. So, it might just be as a sign to say, "Okay, check your process, check what you're doing, revaluate and then kind of go from there." (Dylan, Senior, Biomedical Engineering)

Other incidents in this category showed participants trying out new approaches in response to novel project contexts. In general, the novel elements involved considering specific users, availability of materials and resources, and time constraints. Participants completed new tasks to address these additional considerations and developed a deeper understanding of how the context affects their approach to innovation, but this also led to broader understandings of the innovation process. Ella, for example, began contacting materials vendors to explore the possibility of alternative materials to use in a research and development project. She took it upon herself as the only primarily English-speaking member of the team. From this experience, she not only saw how innovation sometimes requires operations tasks like contacting suppliers, but also how the work conducted during one innovation project (i.e., building relationships with suppliers) contributes to the innovative potential of future projects.

I worked a lot with connecting the team with raw material providers in the U.S. because I speak English, and then using the materials that they sent us. I was trying to find a way to combine them, because they each had these materials that they thought would work but they weren't designed, necessarily, for this problem, so how could I take these maybe good materials and combine them to make a material that actually was. I did a lot of investigation into the different providers, and the different products, and then I received 
them, and then I ran different experiments with combining them, which it seems innovative to me.

Also, just using my connection back here in the states to help the business down there, because I didn't necessarily have to do that. That wasn't requested of me. That was of my own initiative, so looking outside of the business's normal range of focus, or where they're going to find their solution...

It's bringing new ideas, and new perspectives, and new options to the table, which allows everyone to be more innovative. The world opens up a lot more, so you have a lot more choices, and a lot more potential routes, so you can be a lot more innovative when you have this freedom... They were able to look at more options, then also, with this provider, I feel like it allowed innovation in other projects because now that they already had this contact with one provider in particular, here in the U.S., they had all of these other problems that they had realized, but they hadn't really started focusing on yet. After learning more about this provider, and the different products that they had, they realized that they might have solutions for these other ones. It was kind of innovation, both in the project we were working on, because it allowed them more options, but then also it was starting to potentially resolve other problems that you have. That just happened by opening up the world, connecting them to something different. (Ella, Senior, Industrial Engineering)

\section{Immersion in Novel Innovation Ecosystems}

This type of incident involved participants experiencing new contextual elements, reflecting on those elements, and coming to deeper understandings of innovation due to that reflection. In most cases, these incidents brought participants beyond the technical aspects of innovation towards a deeper awareness of business/strategic, user, and/or team elements. Participants also became self-aware of their intimate involvement in many aspects of an authentic project. This deep involvement brought awareness of many previously hidden aspects of innovation. For example, Ella was deeply immersed in an R\&D lab and gained awareness of the role of stakeholders, laws, budgets, and scientific principles.

You keep noticing that there's a problem, or somebody tells you that there's a problem. What they say, or what you originally think is not always the problem, but that alerts your attention to something that's going on. Then figuring out what it is, is a lot about understanding what's going on, so observing or researching. Spending time in the environment or in the problem to find where the root of the problem actually is. And then setting those specifications is so dependent on you and on who you're working with, who you're working for, who you're delivering to. Because then it depends on a whole host of things, the laws, budgets, the laws of physics. Your abilities in the project. (Ella, Senior, Industrial Engineering)

In many cases, cognitive dissonance was a significant aspect of this type of incident. Participants were not only experiencing new aspects of innovation processes and environments, but these new elements conflicted with their previous perspectives. By resolving this internal conflict, 
participants developed deeper understandings of innovation and it's many facets. They also tended to move away from ego-centric approaches. In the example below, Sarah described a common conflict among the participants: an intrinsic desire to develop radically novel solutions as an engineer versus the goal to develop a more reasonable solution that address users' and/or clients' needs. She eventually sided with the latter, in part due to regular interaction with users and a newfound understanding that the fundamental reason for innovation, at least in her experience, was to meet clients' underlying needs.

One of the projects that we are working on right now with our team is a wall at [a children's hospital]. It has this huge image on it for a rehabilitation center. It's all these kids playing. It's a cityscape. It's meant to help distract students from the fact that they're in the hospital, or children from the fact that they're in the hospital and make it fun...

At the beginning of this semester, we got to go down to [the hospital] and sit in front of the wall, basically, and come up with ideas. We got to talk to some of the patients. We got to talk to the doctors there, the nurses, to people that use this every day, and get an idea of what they need. It was very hard not to come up with these crazy cool ideas because they would take forever. One of the ideas that was come up with was to make it have motion sensors going with it, with a storyline...

We were like, "Wow, this is awesome. We are going to do this. It's going to be so cool." You could have touchscreen interactions. You could have whatever else you wanted to put on there. We came up with all these ideas, and then having to go back and think about the restriction that we had... and thinking about what is actually important to these students. It's in a rehabilitation center. Almost all of the children in this area, if they are not severely physically disabled, there is a lot of severe mental disabilities that go there, a lot of brain damage situations. Those complex situations aren't necessarily good for them. As cool as that would be for us, and the doctors and the nurses, it might overwhelm or scare a student, or they may not be able to understand. They said that some of the things they are working on right now are things like one- and two-step tasks...

We don't want to overwhelm them. All of this stimulation might be too much for somebody at some point. It was hard to get away from the idea of, "These are all really cool things that we could do," to say, "What's important for the user," which is always a learning experience for me. (Sarah, Senior, Chemical Engineering)

\section{Learning from Failure}

This category of incidents played as a counterpoint to Learning from Immersion. Whereas the previous incidents resulted from prolonged exposure to novel contexts and approaches, these incidents resulted from reflecting on more acute experiences. Here, participants encountered some degree of failure when applying familiar or chosen approaches and mindsets, reflected on why they failed, and changed their approaches to achieve more success in current and future innovation projects. The two types of incidents within this category, Acute Failure and Responding to Setbacks, differed primarily in the magnitude of the failure. 


\section{Acute Failure}

This type of incident occurred four times total across three participants. While this type of incident was rare, it seemed to be a highly impactful incident for the participants who experienced it. The incidents began with participants approaching innovation projects using extant approaches that they believed would be effective. Through these approaches, they developed technologically advanced prototypes that they felt would address necessary issues, function as expected, and represent novel solutions. However, these prototypes were judged by stakeholders or clients as substantial failures. This failure inspired the participants to critically reflect on their innovation method, often leading to new approaches that encompassed more aspects of innovation (e.g., awareness of the market, connectivity between subsystems, usercenteredness). For example, Elon's failure to meet user needs caused him to take a humancentered approach with future innovation projects.

There's an operator that had to test a specific weld... He did this by taking a huge bar and just manually pulling it down to see how much force it took. He's been doing it for multiple years. It started to really wear him down a little bit. Looking at the process, it's obviously not very safe or ergonomic. I was trying to fix that. I ended up actually talking to him to see what he wanted to have done. He proposed like a really small, a very concise way of fixing it. I basically ignored him... I made some really elaborate fixture for him that probably cost him way too much. It was really bulky and huge.

I remember being frustrated that he didn't like it at all because I kept bringing it to him like, "Hey, you should try this." He didn't really like it. I just started to think, "He's wrong. I'm the engineer. He doesn't know what he's talking about." Then I left, and came back the next [co-op] session, and his module was the way that he wanted it in the first place and my design was just scrapped...

I felt I guess more let down on my end. I knew my mistake. I knew I was just really just ignorant I guess in my design. I didn't really know what I was doing. I felt bad that I had to make him suffer through it while I was trying to figure it out on my own....

Going through a bunch of failed designs and understanding that there comes a point where you're like, “Okay, I'm not taking him into account at all." I think it's just a wall you have to see and then climb over...

I want to say getting your own ambitions out of the way. Selfishness, I guess. Just wanting to make it through your own, because when you're doing that, you're just trying to see what you can do... The bigger picture, I was very self-centered when I first designed. I think being able to expand the level onto a different, larger audience. I think that definitely helps with innovation, because innovation is not really a personal thing. It's more of like a wide body of people being moved by a specific change. (Elon, Senior, Mechanical Engineering) 


\section{Responding to Setbacks}

This type of incident is a less intense version of Acute Failure. Instead of being shocked by failure on a substantial deliverable, participants became aware of smaller-scale failures within their process. They responded to these failures, or setbacks, and recognized how the new approaches led to innovative success on the project. This involved recognizing infeasibility or undesirability of early prototypes or design concepts or experiencing process-related challenges that needed to be overcome. For example, Verdasco described an example of poor team communication leading to overlapping and contradictory design work on a large service learning team. He and his team began to implement frequent, all-hands meetings to keep the sub-teams informed and build cross-team understanding. This incident showed him the importance of communication during innovation projects and provided a concrete process that he associated with innovation.

We have a meeting every Wednesday with the entire team. Because we have an education team, a digester team, and a piping team. So, we have a meeting with all of them on Wednesday and we discuss any concern with each of the teams since all of the work overlaps. And then we have a meeting every Sunday where we discuss just with our team. $[\ldots]$

During the beginning stages, there was a lot of miscommunication issues. We usually never had the Wednesday meeting between all three groups. It was just between the design leads for each group. So, after we implemented that all members show up, it was actually easier because everyone knew what was going on and if they had any concerns we could clear it up immediately...

I would say innovation's not a one-man thing. It's not a one-man team. If you're working in a firm, you can't innovate a product on your own. You can't see concrete progress on it. So, I guess you need to make sure everyone's on the same page as you. And you need to make sure everyone takes the next step at the same time. (Verdasco, Junior, Mechanical Engineering)

\section{Learning from Others}

This category of incidents involved participants developing new understandings of innovation by observing and interacting with others. These observations caused participants to reflect on and modify their own approaches and understandings. Types of incidents in this category included Learning from Collaborators, Reflecting on Historical Examples and Responding to External Evaluation.

\section{Learning from Collaborators}

This type of incident described specific learning based on observations of teammates, clients, users, friends, classmates, and others. These experiences contributed to participants' perceptions of how to (and how not to) engage in innovation. For example, in some cases, participants observed mindsets and approaches among their collaborators that inhibited innovation. As Tony 
described, participants commonly recognized the closed-mindedness or inflexibility of others and how this led to limited understanding of the problem and potential solutions. From these examples, participants began to value open-mindedness and the importance of presenting and acknowledging fresh perspectives during innovation.

You can't constantly innovate if you just pursue one line of thinking. You need to broaden your experiences, broaden your knowledge, broaden your exposure to different people and see what's going on outside. Or just look at what's going on inside with a different perspective. I think that was the biggest take away for me about innovation... The company was just so focused on production and just trying to make as much as volume of bottles of possible that they don't exactly look at how they could find deficiencies within their own system...

Like for example, when I spoke to a few employees working in the lab testing area, they were saying that some of the machinery that they were using used to fail quite a lot and, as a result, it would slow them down sometimes... Those people that had been using that machine for almost, if I had to guess, it would be at least ten years, and they'd never even thought of replacing it. But when I just talked to somebody offhand and said, "Hey you know there might be something new out there." He said, "Yeah, in my previous company I worked with, they were doing such and such with a different part or machine." And that just came across as something that had never been thought before, just because his task was something and his job was something else, he was only focused on that, not focused on something else in the back of his mind, which could have led to a big improvement of the company. (Tony, Senior, Industrial Design).

Alternatively, other participants observed the mindsets and approaches of others that supported innovation. John, for example, described how her internship mentor acted as a role model who demonstrated the importance of making novel association of technical principles to develop innovative ideas (a core aspect of her category: Develop Radically New Technology).

It was just so simple after he explained it. "Yeah, how come no one has done this before?" Because it just made a lot of sense. But it was totally brand new and that was probably the first thing. And then, also, the other thing too was, "Wow you have to be pretty smart to come up with this too." Granted, it was a simple idea but to be able to put these two things together and actually make it work. It's just, you have to know a lot about what already is out there and what is up and coming and you have to be able to push those two worlds together...

I guess the more you know, the more doors that opens, and the more things that you can talk about, the more things you can that you think about, the more things that you can ask questions about. As you can go deeper in your knowledge base, you can connect more to the subjects and things around you. I guess I'm impressed with the amount of knowledge it took. He saw a connection that no one else did and he had to be knowledgeable in order to make those two connections. And the reason no one thought about it before is because no one's had that same background. Not your everyday Joe could think about that walking down the street because he doesn't know a lot about microphones and he doesn't 
know a lot about the new technology and he doesn't know about acoustics in general, and I feel like you definitely need to know in order to make connections...

I originally, before the [microphone] project, I just thought that innovation was a catch word that companies use in order to bring people in and that other people that have more experience and have more industry and were super-duper smart or whatever were the only innovative ones out there. I guess what changed this project for me was anyone can be innovative, you just have to know things and put them together. (John, Senior, Acoustical Engineering)

\section{Reflecting on Historical Examples}

Eight participants demonstrated 11 examples of applying messages from historical stories of innovation to their own work. In these incidents, participants were aware of how innovation occurred, or how it was defined, based on some individual or company's prior success. Examples included Steve Jobs and various Apple products, Thomas Edison and the light bulb, and Mark Zuckerberg and Facebook. Participants connected the processes and outcomes intrinsic to these stories and used those examples to guide their own processes, or, more commonly, develop an understanding of how the work they were doing connected to innovation. For example, Sarah connected the evolution of the iPhone product line to her innovation work. She described how each subsequent model improved upon previous models, in part due to human-centered design processes. She used this to connect her human-centered design work to innovation and understanding how making small advancements, based on meeting user needs, was a strong path to sustainable innovation.

It's not necessarily always starting from nothing. You can innovate on something. Coming into engineering, I would've said that innovation is when you make something. I probably would've said being an entrepreneur would go right along with being innovative. I would think that, to be innovative, you have to come up with something brand new and be the Steve Jobs of the world that made the iPhone. That's innovative. But coming into this project, I realized that innovation can be improving something. More often than not, that's what it becomes. Sometimes it's more effective to improve on something than to create something from scratch.

In everything, I think, in general, usually the second generation of a piece of equipment is better than the first. If you look at the entire iPhone spectrum, they've improved over time, and I would say that each one of those improvements is an innovation in itself. The original creation might've been extremely innovative to begin with, creating something that combines devices. I don't think that's the only innovation that came along in the process. Introducing fingerprint scanners onto that, that's an innovation. Introducing whatever they've done now with the 3-D touch interaction that you can have with an iPhone, that's an innovation that's going to make a difference in how someone works with it. Understanding that side of things would be the biggest thing that has changed about my perspective since working on these kinds of projects. (Sarah, Senior, Chemical Engineering) 


\section{Responding to External Evaluation}

There were two examples of this critical incident within the dataset. In this incident type, participants received feedback on their innovation projects from individuals who were not involved in those projects. This feedback was typically informal, but came from authoritative sources (e.g., a respected instructor). The unexpected feedback caused the participants to reflect on their work, resulting in new understandings of the nature of innovation and how their work connected to innovation. In the example below, Esteban discussed a personal project (a 3-D printed longboard) with an instructor. This exchange helped him realize that his work was innovative, but more importantly, expanded his understanding of innovation beyond product to process.

Longboarding, it's primarily wood boards. You can see mine is bamboo. So, the fact that I used something that nobody ever considered to make a longboard out of that in itself is innovative...

That's actually how I struck up a conversation with [my engineering instructor]. I was like, "I'm working on this project. Do you know anybody that would be interested in that?" And he was like, "No, I don't know anyone that would do that." I guess the fact that he said no one else he knew would do that showed that I was innovating somehow. If no one else is thinking like that or is thinking of doing something like that, then that's innovation in itself, starting up a new idea, a new conversation...

It changed how I thought about innovation because it's not coming up with something really new. It's not a new product. It's not a new idea. It's just a new way of doing. No one has ever 3D printed a longboard. [My engineering instructor] was like, "I don't know anyone that would do that." So, innovation changed from a product that's completely new to a new way of doing, a new way of thinking about it. (Esteban, First-Year Engineering)

\section{Learning from Success}

The previous three categories of critical incidents saw participants developing new understandings of innovation as they worked through challenges of their extant approaches, when experiencing failure or setbacks, and as they became aware of or grappled with novel perspectives from others. The three types of critical incidents in this category saw participants reflecting on their natural approaches that resulted in successful innovation. These types included Reflection on Project Conditions, "Hey, That Worked," and "I'll Do It My Way."

\section{Reflection on Project Conditions}

This type of incident was observed across 11 participants and included 26 total incidents. In this incident type, participants reflected on the entirety of one or more projects to better understand the contextual conditions that supported or did not support innovation. Most frequently, participants contrasted successful innovation projects with unsuccessful or non-innovative 
projects. For example, Dylan contrasted the opportunity for innovation during his senior design project with the restrictions of his laboratory coursework.

In some instances, there are places for innovation and there are some places where you just have to produce a product, I feel like. So, in lab courses, they just want to see that you can do the process that they've taught you over the semester. So, there's no point in innovation there. It's just, "Make a product that can get you the A." Whereas in the senior design project you want to get the A, but you're also given a lot of room for innovation because there technically is no restraint. There's no, "Show us what you've learned." It's more like, "Come together. Put an idea together. Do X, Y, and Z. And get your final product out there." And if it's innovative, great, but you don't get dinged for innovative or not in terms of a grade. So, you can work those two together, where it's like, "Okay, let's just put it together this very good product hopefully its innovative," and then go from there. (Dylan, Senior, Biomedical Engineering)

Students often self-reflected or compared between open-ended projects from internships, cocurricular experiences, or dedicated design courses with less flexible activities (e.g., cookbook labs). By reflecting on these experiences, students tended to develop an understanding of innovation as stemming from their autonomy and flexibility of project topic and direction. Additionally, students often recognized the conditions under which they, as individuals or the teams they worked on, were most likely to contribute to innovation. These conditions varied, but often featured some combination of sufficient technical expertise, alternative/diverse perspectives, and alignment with personal and professional interests and motivations. Several participants, such as Taylor, began to reflect on and note the important role a team played in their innovation work. She described how a diverse team of hers integrated a variety of expertise and perspectives that supported the innovative work guided by the unique interests of the team members.

I would say diverse interests, because I want to have something that's going to appeal to a wide audience, right? So maybe something I'm interested in isn't as appealing to the rest of the world, but then like if we mixed it with something Donald [a teammate] likes, then maybe it will be a lot more successful... We all have different hobbies, we all have different things we do, we all have different areas of research or whatever, but then we're all aligned on the same page for what the goal is, what discrete deliverables we need at the end of the project...

Realizing how important your team is was also a big thing for me. I've been friends with Donald and James since sophomore year... but we never really had a chance to think outside the box. It was always, "Analyze this circuit, what's the resistance, what's the capacitance, blah, blah, blah," and there was a right answer. But whereas with the project we were like, "oh, we actually have a chance to think creatively," it was a lot more of using all our personalities together. So, I realized how important it was to have a team that had diverse experiences. Like I mentioned how we had different interests and technical abilities, and then being able to synthesize those together. And then this semester, on the ASIC, application specific integrated circuit, design class that I'm in right now... 
The people I'm working with aren't people that I click with per se, and so we'll see how it turns out. We start this week and it ends at the end of the semester. I have a feeling it may not turn out as fabulously as the car did... I realized that who you're working with on the innovation is important as what you're making. And it changes the project actually, just to pull out that a little more. So, the one that we're working on we're going to do something with [a unique web protocol]. And the reason we are doing that is because one of my partners/new friends used to work at a [company that specializes in the unique web protocol], so he knows all about how those things work. So that's the reason that were doing that project, because he brought it to the table and he knows stuff about it and you're like, "Okay, well we'll do that," I would have never thought about that, I don't have experience in that. (Taylor, Senior, Computer Engineering)

\section{"Hey, That Worked"}

This type of incident shared some similarities with the Trying New Approaches type within the Learning from Immersion category. Both involved participants taking specific approaches to their projects, achieving innovative success, and recognizing that the approach they took supported innovation. A key difference is that the approaches in this type were not new but rather were prior approaches or strategies that the participants already tended to utilize. They often did not attempt innovation through these methods. They simply applied their natural approaches to a project and these tended to result in innovation. In other words, the result of innovation came as a pleasant surprise as they engaged in "ordinary" problem-solving. Dylan, for example, enjoyed ideating and often used prior art as a technique. In the example below, he described how using prior art led to his team's innovative idea of halving a balloon to innovate upon a common ventricular device. Dylan used this example to describe the role imagination played in innovation.

When you have a stent, you're effectively going to have it and have your catheter, and typically you're going to have it like this. And you're just going to have a full balloon in it, where it expands and it collapses with the pressure gradients. Ours is, basically, we have a box and it's half a balloon, and now you're expanding first off within rather than relying on the external, and it's just moving in and out. But you're only using half of a balloon, so you're saving cost of materials and it allows you to create a product that actually sticks more to the walls of the ventricle. That's where the imagination came from. I mean, who cuts a balloon in half? Why would you do that? We used imagination; that's how we got the idea...

When we were looking at some of the other products we were like, "What are their core fundamentals for how they work and how they operate?" And we realized that a balloon would be a good way to go about it. So, then we were thinking of different uses for it, and that's when the imagination came in. How can we incorporate it into our idea? ...

It definitely comes around a lot. I mean, whether it's an internship, or a lab, or even answering the basic textbook questions, you sometimes have to get very imaginative to answer those questions. 


\section{“I'll Do It My Way"}

As above, this type of incident focused on participants using their natural or preferred approaches during innovation projects. A key difference was the participant attitude toward the approach. Here, participants ignored opposition from others (typically supervisors or instructors) or potential misalignment with project conditions. They remained confident, resolute, and (often) determined to prove their way was effective. In 18 total incidents across 7 participants, individuals perceived themselves as correct. For example, Matt promoted what he called a "barnyard engineering" approach. His utilization of the approach prevailed despite the opposition of a shop manager and suggestions from instructors across five distinct experiences. For example, in the example below, he describes how his trial-and-error approach conflicted with the warnings of a machine shop manager during prototyping.

He was discouraging us from a method of machining. We had a longboard wheel, and we wanted to use the lathe to bore out the internal diameter, to make a plate fit into it... To do that, because the plate needed to fit three bolts into it, and we needed the plate so big, and we needed the tube so big, that we needed to bore out the internal diameter. He was just like, "This isn't going to work. You're going to break something." ...

We pretty much just said, "Hey! If we're going to break our part, and it's not going to hurt anyone, it's not going to hurt your equipment, because it's a very soft material, just let us break our part. If we're going to screw up, let us screw up." They were pretty much like, "All right. Fine." ... We bored it out, no one got hurt, nothing broke. Put our plate in, fit perfectly. What do you know? ...

The entire team just came and was like, "Well, we know what we're doing. We may not be able to explain it well enough for you, but we know how we want to make it work, and we know that we want to make it work, and we're willing to put our money where our mouth is and take our chances."

Part of getting experience is screwing up, learning what doesn't work. At least from the repair side of things, which needs a lot of innovation, it takes ... The more experience you get, the more you can say, "Okay, I've seen this problem before. This is how I fixed it." Or, "I've seen this problem, but this is different by this, so I can mold the two and be a little creative with how I want to do it." Really, it's just developing a way in your mind how you want to make something work, even though it may not be the orthodox way, because sometimes the unorthodox way is the best way, even though it's a little harder to get past people in charge, who only want to do this set way. (Matt, Senior, Mechanical Engineering)

The success of these approaches reaffirmed their effectiveness towards innovation, often in new, or marginally new, contexts. Thus, these incidents did not change one's understanding of innovation as much as it did expand that understanding. They provide an important counterpoint to the incidents with Learning from Failure, in which these natural approaches led to negative results and caused deeper reflection on one's process. Thus, these incidents may be considered 
precursors to Learning from Failure incidents that may later deepen the effect of failure on the individual and, potentially, the quality of reflection and change.

\section{Investigation of Incident Types by Way of Experiencing Innovation}

While it is beyond the scope of this study to confirm how critical incidents informed participants' ways of experiencing innovation, several trends were evident when mapped to the original outcome space (see Figure 1). The following sections describe trends related to comprehensiveness of categories of description, focus area prioritization, and specific categories. We present this discussion to inform more nuanced future explorations and to inspire reflection rather than as a guidebook for promoting specific types of understandings of innovation.

\section{Comprehensiveness of Way of Experiencing Innovation}

On average, participants who demonstrated more comprehensive ways of experiencing innovation (Categories 5-8) reported more critical incidents $(m=8.25)$ and more distinct types of critical incidents $(m=4.38)$ than the participants in less comprehensive categories $(m=$ 6.75 and $m=3.75$, respectively). This observation connects to a previous qualitative finding that demonstrated how participation in more complete and nuanced projects often supported more comprehensive ways of experiencing innovation ${ }^{14}$. A low sample size limited the power of a statistical test, so this observation only suggests that future work may target a quantitative analysis to explore the relationship between volume and variety of critical incidents and development of innovation understanding. We do not claim that these findings confirm such a relationship but rather the potential for such a relationship.

It is important to note that development towards more comprehensive understandings of innovation are not solely about what students' experiences provide, but also about what students brings to that experience ${ }^{14}$. A more meaningful trend related to comprehensiveness may be that two types of incident ("Hey, that worked!" and Observing Colleagues) were more common (and relatively evenly distributed) among the four most comprehensive categories. Both incident types represent students reflecting on, acknowledging, and making sense of how they and their collaborators/peers achieved innovative outcomes. Thus, reflecting on actions taken during successful innovation projects may be a substantive contributor to student growth in this area.

\section{Focus Area}

Differences in critical incident types were also evident across focus areas of the outcome space (i.e., prioritizing technical aspects of innovation vs. prioritizing human and/or enterprise aspects of innovation). Of the 38 total incidents in the Learning from Immersion category, 27 were from the six participants in Categories 4-6 (i.e., those that prioritized human and enterprise aspects of innovation projects). Conversely, the technical aspect-focused categories $(1-3,7$, and 8$)$ contained all 18 incidents of "I'll Do It My Way" and 10 of 11 incidents of Reflecting on Historical Examples. 
The critical incidents that comprised the Learning from Immersion category demonstrated students developing a deeper understanding innovation by going outside their comfort zones and experiencing innovation in novel contexts and through novel approaches. These incidents seemed to lead participants towards deeper integration of user-centered and business-centered actions and considerations. The categories of "I'll Do It My Way and Reflecting on Historical Examples show participants deepening their understanding of innovation through applying and/or familiarizing themselves with approaches that have proven successful for themselves or others. These incidents tended to enhance participants' technical expertise and their ability to apply it to the development of personally or globally novel technological solutions.

The above observations suggest that different individuals are likely to connect with innovation in different ways, and that the pathway one takes in their innovation development can substantively influence the aspects of innovation one prioritizes. Moreover, the incidents themselves suggest tendencies to either (1) explore new contexts, especially for students in Categories 4-6, or (2) follow proven and preferred approaches. This is not to say there are only two pathways to develop deeper ways of understanding and experiencing innovation, but that general trends are evident. Future research may explore these and other potential pathways, the influence of individual tendencies and their environments on the pathways, and how individuals with tendencies toward one pathway might react to and be influenced by interventions related to another pathway. For example, how might students aligned with Category 3 benefit from projects that nudge them to engage with and reflect upon innovation contexts that feature stronger human- and enterprise-oriented elements?

\section{Specific Ways of Experiencing Innovation}

Despite general trends in comprehensiveness and focus areas, many of the categories demonstrated disparate profiles of incidents. Other than Categories 5 and 7, both participants in each other category reported several different types and quantities of incidents. For example, in Category 1, Matt described only two different types of critical incident: Reflection on Project Conditions (3 incidents) and "I'll Do It My Way" (5 incidents), while Jerry reported five different types of critical incident, sharing only one incident of "I'll Do It My Way" with Matt. This observation suggests that one's journey toward a specific way of experiencing innovation is likely to be unique rather than formulaic. Students may experience innovation and innovation learning across different settings and in different ways, and a diverse range of critical incidents may be the best way to reach a variety of students.

However, both members of Categories 5 and 7 demonstrated similar profiles of critical incidents. In Category 5, both participants reported two instances of Try New Approach, at least three instances of Immersion in a Novel Innovation Ecosystem, and at least one instance of Observing Colleagues. In Category 7, both participants reported five instances of Reflection on Project Conditions and one instance of Try New Approach and Reflecting on Historical Example. It is important to note that participants who comprised Category 5 came to their innovation projects seeking new experiences that challenged them to engage with new cultures, technical domains, functional roles, and stakeholder groups. In contrast, participants who comprised Category 7 typically described in-class design projects (e.g., capstone design) wherein they expanded upon and synthesized their previous learning, often in more complex and authentic settings. These 
types of experiences tended to inspire them to apply time and effort that was uncommon of their previous in-class project experiences.

These observations suggest that specifically designed and sequenced experiences may support development into specific ways of experiencing innovation. In some instances, techniques may require alignment with students' willingness (rather than resistance) to engaging in those ways of experiencing innovation. For example, setting up student projects across new settings and requiring disparate approaches may only help willing students (especially those who prone to some observational learning) develop towards Category 5, whereas some students may oppose the novelty and seek to simply do it their way. However, more work needs to be done to understand if and how the preliminary "recipes" of critical incidents could support such growth and which students might benefit most from those lessons.

\section{Closing Discussion}

In this paper, we sought to address the research question, "What aspects of engineering students' innovative experiences were critical to the development of their ways of experiencing innovation?" This paper is a direct extension of a previous study ${ }^{13,14}$ wherein eight different ways of experiencing innovation were extracted through semi-structured interviews and phenomenographic analysis. Here, we applied Critical Incident Technique to a subset of those interviews $(\mathrm{n}=16)$. We purposefully selected participants to maximize variety in way of experiencing innovation (see Figure 1), gender, major, and year in school.

Our initial interest in applying Critical Incident Technique was one of feasibility. We questioned, "Can we utilize this technique to help identify what underlying causal factors promote student progression along the established outcome space?" Specifically, as shown in Figure 1, students were grouped into one of eight categories which represented variations in their ways of experiencing innovation. We theorized that critical incidents were primary sources of movement from less to more comprehensive ways of experiencing innovation.

We identified a nearly exhaustive set of categories and incident types (which is a sign of quality in a critical incident study ${ }^{17}$ ). We state "nearly" as we noted that we were unable to group 18 incidents beyond the 122 reported here. Hence, the four categories and 10 incident types encapsulate roughly $87 \%$ of the incidents extracted. Further, we observed preliminary trends that connected specific incident types (and groups thereof) to different ways of experiencing innovation, focuses of innovation activities, and comprehensiveness of way of experiencing innovation. These results suggest that critical incidents may provide a useful tool for educators seeking to facilitate innovation learning and development among students and researchers hoping to understand this process.

One way to operationalize these results would be to structure learning activities to support student experiences related to these critical incidents. For example, 11 of 16 participants were grouped into two incident types: Trying New Approaches and Reflection on Project Conditions. A basic application of these incident types could entail a semi-structured project that guides students through a new approach to innovative design and incorporates sense-making activities (such as group discussions or journaling) so they can reflect on why and how the new approach 
they utilized and the environment in which the project was situated may have contributed to (or inhibited) innovative outcomes.

It should be noted, that while Trying New Approaches and Reflection on Project Conditions were relatively common, they were not necessarily the most powerful contributors to student innovation learning. Hence, as future educators seek to promote innovation among their students, they may begin by providing students with experiences related to these types due to their greater accessibility. In addition, instructors might venture into rarer, but potentially potent incidents such as Acute Failure ${ }^{14}$. Further, as we recognize that learners have various learning styles, and participants in this study demonstrated a variety of critical incident profiles, an ideal approach to promoting student innovation would seek to incorporate multiple experiences or amalgamations of the experiences described herein. For example, providing students with opportunities to both fail and succeed can be mutually reinforcing.

A focus on immersive learning experiences seems especially pertinent for promoting student innovation. This finding aligns directly with the results generated by Zoltowski and colleagues ${ }^{22}$ who explored variation in students' ways of experiencing human-centered design. However, in that study, Zoltowski and colleagues described immersive and critical experiences as two separate groups. Many of the respondents in this study challenged our a priori conception of criticality that was based on this framing. Specifically, students in this study tended to reflect holistically on experiences and struggled to discern a specific point in time when they experienced an epiphany or "a-ha" moment that they could state or where we could infer, "That is when I became innovative." Thus, while critical incidents represent important "moments" in a students' learning and development, they should be thought of as parts of a journey.

Students' journeys towards becoming innovators were complex. While we have identified some potential trends, more work needs to be done to understand how these trends emerged, how they informed one's way of experiencing innovation, and how they can be leveraged to support innovation education. In future research, we hope to map the student incidents to project conditions, individual characteristics, and specific learning outcomes to indicate if and how certain types of experiences were more conducive to more comprehensive ways of experiencing innovation, which types of incidents were most meaningful for specific types of learning (e.g., risk-taking behavior, variety in ideation), and which types of incidents were most meaningful for individual students.

\section{Acknowledgment}

This material is based upon work supported by the National Science Foundation Engineering Education Program under Grant No. 1150874. Any opinions, findings and conclusions or recommendations expressed in this material are those of the authors and do not necessarily reflect the views of the National Science Foundation. 


\section{References}

1. Dahm, K., Riddell, W., Merrill, T., Harvey, R., \& Weiss, L. (2013). Implementing entrepreneurial assignments in a multidisciplinary, sophomore-level design course. Advances in Engineering Education, 3(3).

2. Duval-Couetil, N., \& Dyrenfurth, M. (2012). Teaching students to be innovators: Examining competencies and approaches across disciplines. International Journal of Innovation Science, 4(3), 143-154.

3. West, R. E., Tateishi, I., Wright, G. A., \& Fonoimoana, M. (2012). Innovation 101: Promoting undergraduate innovation through a two-day boot camp. Creativity Research Journal, 24(2-3), 243-251.

4. Gerber, E. M., Olson, J. M., \& Komarek, R. L. D. (2012) Rethinking how students prepare for careers in innovation: A case study of extra-curricular design-based learning. International Journal of Engineering Education, 28(2).

5. Cropley, D. H. (2015).Creativity in engineering: Novel solutions to complex problems. San Diego, CA: Academies Press.

6. Daly, S. R., Mosyjowski, E. A., \& Seifert, C. M. (2014). Teaching creativity in engineering courses, Journal of Engineering Education, 103(3), 417-449.

7. Genco, N., Hölttä-Otto, K. \& Seepersad, C. C. (2012).An experimental investigation of the innovation capabilities of undergraduate engineering students, Journal of Engineering Education, 101(1), 60-81.

8. Fila, N. D., Hess, J. L., Mathis, P. D., \& Purzer, Ș. (2015). Challenges to and Development of Innovation Discovery Behaviors Among Engineering Students. Paper presented at the 2015 ASEE Annual Conference and Exposition, Seattle, WA.

9. Fila, N. D., \& Purzer, Ș. (2014). The relationship between team diversity, idea variety, and potential for design innovation. International Journal of Engineering Education, 30(6A), 1405-1418.

10. Ferguson, D.M., Jablokow, K.W., Ohland, M.W., Purzer, S. \& Menold, J.D. (2015). Using a Delphi study to confirm characteristics of an engineering innovator. in 2015 ASEE Annual Conference \& Exposition (Seattle, WA).

11. Golish, B. L., Besterfield-Sacre, M. E., \& Shuman, L. J. (2008). Comparing Academic and Corporate Technology Development Processes*. Journal of Product Innovation Management, 25(1), 47-62.

12. Atkins, L. et al., (2015). Fostering Innovative Skills within the Classroom: A Qualitative Analysis from Interviews with 60 Innovators. Paper presented at the 2015 ASEE Annual Conference and Exposition, Seattle, Washington.

13. Fila, N. D. (2017). A phenomenographic investigation of the ways engineering students experience innovation (Doctoral dissertation). Purdue University, West Lafayette, IN.

14. Fila, N. D., \& Purzer, Ș. (2017). Exploring connections between engineering projects, student characteristics, and the ways engineering students experience innovation. Paper presented at the 2017 ASEE Annual Conference and Exposition, Columbus, OH.

15. Braun, V., \& Clarke, V. (2006). Using thematic analysis in psychology. Qualitative Research in Psychology, 3(2), 77-101.

16. Flanagan, J. C. (1954). The critical incident technique. Psychological bulletin, 51(4), 327-358. DOI: $10.1037 / \mathrm{h} 0061470$ 
17. Butterfield, L. D., Borgen, W. A., Amundson, N. E., \& Maglio, A.-S. T. (2005). Fifty years of the critical incident technique: 1954-2004 and beyond. Qualitative Research, 5(4), 475-497.

18. Marton, F., \& Booth, S. (1997). Learning and awareness. NJ: Lawrence Erlbaum Associates.

19. Bowden, J. A., \& Green, P. (Eds.). (2005). Doing developmental phenomenography. Melbourne, Australia: RMIT University Press.

20. Hess, J. L., Strobel, J., \& Brightman, A. (2017). The development of perspective-taking in an engineering ethics course. Journal of Engineering Education, 106(4), 534-563.

21. Ashworth, P., \&Lucas, U. (2000). Achieving empathy and engagement: A practical approach to the design, conduct and reporting of phenomenographic research, Higher Education, 25(3), 295-308.

22. Zoltowski, C. B., Oakes, W. C., \& Cardella, M. E. (2012). Students' Ways of Experiencing Human-Centered Design. Journal of Engineering Education, 101(1), 28-59. 